\title{
UTILIZAÇÃO DE ÍNDICES CONTÁBEIS NA DETERMINAÇÃO DO RATING
}

\author{
ARAÚJO, Camila Curti de ${ }^{1}$ \\ GAIO, Luiz Eduardo ${ }^{2}$
}

\begin{abstract}
RESUMO: Este trabalho tem como objetivo fazer a classificação de rating da Fitch Rating, da Moody's e Standard \& Poor's (S\&P), por meio do uso de índices contábeis e financeiros, e com isso estimar o nível de rating das empresas que não são acompanhadas por essas agências, e possibilitar estimação do nível de rating de companhias que não possuem nenhuma avaliação de crédito. Para isso, foram coletados dados de demonstrativos contábeis do ano de 2009, de empresas brasileiras. A metodologia utilizada refere-se a uma pesquisa descritiva. Para a determinação do rating, foi utilizado o modelo probito ordenado em painel. As variáveis explicativas utilizadas foram o Dummy, indicando se a empresa tem ações que fazem parte do Índice da Bolsa de Valores de São Paulo (Ibovespa), o Ativo Total da empresa, a capacidade de pagamento, o endividamento, a margem operacional e o retorno sobre o ativo. As variáveis que melhor explicam os ratings através do uso de índices contábeis foram o Dummy, que indica a presença da empresa no Ibovespa, o tamanho da empresa e a cobertura de juros.
\end{abstract}

Palavras-Chave: Ratings de crédito. Agências de Rating. Risco de crédito. Probito ordenado.

SUMMARY: This paper aims to classify rating from Fitch Rating, the Moody's and Standard \& Poor's (S \& P) through the use of accounting ratios and financial resources, and thereby estimate the level of rating companies that are not accompanied by suchagencies, and enable estimation of the level of rating companies that have no credit rating. For this, data were collected from financial statements of 2009, Brazilian companies. The methodology was a descriptive analysis, qualitative, based on the technique used was a literature search, where the theoretical framework involved the following topics: credit risk, the definition of rating, rating scales, rating classification models. To determine the rating, we used the ordered probit panel. The explanatory variables used were: Dummy indicating whether the company has shares that are part of the Index of the Stock Exchange of Sao Paulo (Bovespa), the total assets of the company's ability to pay, debt, operating margin and return on the asset. The variables that best explain the ratings through the use of accounting ratios were the dummy, which indicates the company's presence in the Bovespa index, firm size and interest coverage.

Keywords: Credit ratings. Rating agencies. Credit risk. Ordered probit.

\section{INTRODUÇÃO}

Em todo o mundo, os executivos responsáveis pela política de crédito enfrentam desafios complexos relacionados ao gerenciamento de riscos. O rating é uma ferramenta que oferece aos profissionais dessa área uma maneira eficiente de analisar os riscos de crédito de uma empresa, para que estes possam avaliar seus resultados, utilizando dados de forma a auxiliá-los na tomada de decisão (S\&P, 2009).

Os sistemas de ratings compreendem classificações em níveis de risco fundamentados em uma série de fatores, em que se atribuem notas a esses determinados quesitos, e uma nota final a um conjunto de quesitos analisados (SILVA, 2003). Assim, a avaliação econômico-financeira da empresa, a sua participação de mercado, entre outros, determina o risco deste cliente a partir de dados técnicos sobre a sua capacidade futura de pagamento e suas condições de cumprir com seus compromissos assumidos (PAZZINI et al, 2008). Assim, um rating procura sintetizar aspectos qualitativos e quantitativos dos emissores ou emissões (DAMASCENO, 2007).

\footnotetext{
${ }^{1}$ Bacharel em administração de empresas

${ }^{2}$ Pós-Dr. em Administração. FUNDACE/USP; UNIFACEF; FFCL/FE.
} 
Este trabalho tem como objetivo fazer a classificação de rating da Standard \& Poor's (S\&P), Moody's e Fitch Rating, por meio do uso de índices contábeis e financeiros, e com isso estimar o nível de rating das empresas que não são acompanhadas por essas agências.

Para isso, foram coletados dados de demonstrativos contábeis do ano de 2009, de empresas brasileiras. A metodologia utilizada foi uma análise descritiva qualitativa. Segundo Gil (2002, p. 42), pode ser classificado como pesquisa descritiva àquelas que visam descobrir a relação entre variáveis, que tem como característica o estudo de um grupo ou uma amostra.

Com base na técnica utilizada, foi feita uma pesquisa bibliográfica buscando levantar dados em sites relacionados ao assunto, tais como: ANBIMA - Associação Brasileira das Entidades dos Mercados Financeiro e de Capitais, CVM (Comissão de Valores Mobiliários), dentre outros.

Para a determinação do rating, foi utilizado o modelo probito ordenado em painel. As variáveis utilizadas foram o Dummy, indicando se a empresa tem ações que fazem parte do Índice da Bolsa de Valores de São Paulo (Ibovespa), o Ativo Total da empresa, a capacidade de pagamento, o endividamento, a margem operacional e o retorno sobre o ativo.

\section{REFERENCIAL TEÓRICO}

\subsection{Risco de Crédito}

Caouette et al. (1999) afirmam que o risco de crédito é a chance de que essa expectativa não se cumpra. De forma mais específica, o risco de crédito pode ser entendido como a possibilidade de o credor incorrer em perdas, em razão de as obrigações assumidas pelo tomador não serem liquidadas nas condições pactuadas.

Segundo Bessis (1998), o risco de crédito pode ser definido pelas perdas geradas por um evento de default do tomador ou pela deterioração da sua qualidade de crédito. Há diversas situações que podem caracterizar um evento de default de um tomador. O autor cita como exemplo, o atraso no pagamento de uma obrigação, o descumprimento de uma cláusula contratual restritiva (covenant), o início de um procedimento legal como a concordata e a falência ou, ainda, a inadimplência de natureza econômica, que ocorre quando o valor econômico dos ativos da empresa se reduz a um nível inferior ao das suas dívidas, indicando que os fluxos de caixa esperados não são suficientes para liquidar as obrigações assumidas.

Para Brito e Assaf Neto (2008), a mensuração de risco de crédito é o processo de quantificar a possibilidade de a instituição financeira incorrer em perdas, caso os fluxos de caixa esperados com as operações de crédito não se confirmem. "Os modelos de risco de crédito compreendem ferramentas e aplicações que têm por objetivo principal mensurar o risco de tomadores e transações individuais ou de uma carteira de crédito como um todo" (BRITO; ASSAF NETO, 2008).

Brito e Assaf Neto (2008), diz ainda que, os modelos de classificação de risco buscam avaliar o risco de um tomador ou operação, atribuindo uma medida que representa a expectativa de risco de default, geralmente expressa na forma de uma classificação de risco (rating) ou pontuação (escore). Os modelos de classificação de risco são utilizados pelas instituições financeiras em seus processos de concessão de crédito.

\subsection{Definição de Rating}

Segundo Securato (2002) as agências classificadoras são empresas que fornecem serviços de análise, operando sob os princípios de independência, objetividade, credibilidade e disclosure, ou seja, a divulgação de informações sobre determinada empresa, seu desempenho financeiro passado, as previsões 
futuras, as operações atuais, os riscos e benefícios, com o objetivo de auxiliar a tomada de decisão. "Tais agências especializam-se na avaliação da capacidade creditícia de emissores de títulos[...]" (CAOUETTE et al, 2000).

Para Aguiar (1999, p.5) classificação é uma opinião sobre a capacidade futura, a responsabilidade jurídica, e a vontade de um emitente efetuar dentro do prazo pagamento de um principal e juros de um título específico de renda fixa. A classificação avalia a probabilidade de inadimplência do emitente em relação ao título imobiliário até seu prazo de vencimento que, dependendo do instrumento, pode ser uma questão de dias, ou 30 anos ou mais. Além disso, as classificações a longo prazo incorporam uma avaliação da expectativa de perda monetária em caso de inadimplemento.

De acordo com Standard \& Poor's (2002), rating é uma opinião sobre a qualidade creditícia de um devedor com respeito a obrigações financeiras, levando em conta as características dos emissores e seus garantidores e eventuais formas de garantias, e levando em conta, também, a moeda na qual o instrumento de crédito esta referenciado.

Já para Fitch Ratings (2005), os ratings de crédito da Fitch Ratings constituem uma opinião quanto às condições de um emissor ou de uma emissão de títulos em honrar seus compromissos financeiros, tais como, pagamento de juros, de dividendos preferenciais e de pagamento de principal, no prazo esperado. São aplicáveis a uma variedade de emissores e emissões, incluindo, mas não se limitando a paises, estados, municípios, operações estruturadas, instituições financeiras, empresas, títulos de dívida, ações preferenciais e empréstimos bancários. Também medem a capacidade de empresas seguradoras e garantidores em honrar suas obrigações.

SR Rating (2004) define rating como uma opinião técnica independente sobre o risco de crédito de uma obrigação ou conjunto destas. Em outras palavras, o rating mede a probabilidade de pagamento pontual dessas obrigações. Para o classificador de riscos, a pontualidade do pagamento é o que mais importa. Uma obrigação não paga dentro do prazo certo é um título em default. Uma análise de rating é sempre voltada para o futuro. A capacidade de pagamento vai depender de variáveis cujo comportamento precisa ser projetado no tempo.

Brito e Assaf Neto (2008) estudaram modelos de classificação de risco, onde foi observado que os modelos de previsão de insolvência geralmente se baseiam em técnicas estatísticas de análise multivariada, como regressão linear, análise discriminante e regressão logística. Também afirmam que um tipo de variável tradicionalmente utilizada para discriminar empresas solventes e insolventes são índices econômico-financeiros calculados a partir das demonstrações contábeis. Índices são relações entre contas ou grupos de contas das demonstrações contábeis que têm por objetivo evidenciar determinados aspectos da situação econômica e financeira da empresa em questão.

Segundo a SR Rating (2004) embora o rating tenha a finalidade de pontuar o risco, ele é diferente do score, que representa notas obtidas a partir de índices e pesos previamente testados, utilizando parâmetros conhecidos, onde a nota é relacionada a uma classificação. É um processo exclusivamente quantitativo, geralmente baseado em dados passados e públicos. Enquanto que, o rating leva em conta, além dos dados passados, projeções e planos da entidade, fazendo uma extensa análise qualitativa.

\subsection{Escalas de rating}

As escalas de rating não diferem substancialmente de uma agência para outra. São representadas por letras que vão de AAA a D. O quadro 01 resume o significado de cada classificação. A agência Moody's tem uma sequência um pouco diferente (Baa ao invés de BBB, por exemplo), mas o significado permanece semelhante. Os sites na Internet das agências trazem suas definições detalhadas (PAIVA 2006).

Nucleus,v.13,n.1,abr.2016 
De acordo com Paiva (2006), as escalas ainda podem receber sinais (+) ou (-) para indicar a posição relativa de um crédito dentro da categoria de classificação. Porém, a agência Moody's, utiliza números $(1,2$ e 3$)$ ao invés de sinais.

Quadro 01: Definição dos graus na escala de Rating

\begin{tabular}{|c|c|c|c|c|c|}
\hline \multicolumn{3}{|c|}{ Grau de Investimento } & \multicolumn{3}{|c|}{ Grau Especulativo } \\
\hline $\begin{array}{c}\text { S\&P e } \\
\text { Outras } \\
\text { Agências }\end{array}$ & Moody's & Interpretação & $\begin{array}{c}\text { S\&P e } \\
\text { Outras } \\
\text { Agências }\end{array}$ & Moody’s & Interpretação \\
\hline AAA & Aaa & $\begin{array}{l}\text { Altíssima qualidade, com } \\
\text { mínimo risco de crédito. } \\
\text { A capacidade de } \\
\text { pagamento dos } \\
\text { compromissos é } \\
\text { extremamente forte. }\end{array}$ & $\begin{array}{l}\mathrm{BB}+ \\
\mathrm{BB} \\
\mathrm{BB}-\end{array}$ & $\begin{array}{l}\mathrm{Ba} 1 \\
\mathrm{Ba} 2 \\
\mathrm{Ba} 3\end{array}$ & $\begin{array}{l}\text { Elementos especulativos } \\
\text { sujeitos a risco de crédito } \\
\text { substancial. Menos } \\
\text { vulneráveis do que outras } \\
\text { emissões especulativas. } \\
\text { Entretanto, em face de maior } \\
\text { incerteza ou exposição a } \\
\text { adversidades financeiras, } \\
\text { econômicas e de negócios, } \\
\text { podem levar a uma } \\
\text { capacidade inadequada de } \\
\text { pagamento da contraparte. }\end{array}$ \\
\hline $\begin{array}{l}\mathrm{AA}+ \\
\mathrm{AA} \\
\mathrm{AA}-\end{array}$ & $\begin{array}{l}\text { Aa1 } \\
\text { Aa2 } \\
\text { Aa3 }\end{array}$ & $\begin{array}{l}\text { Alta qualidade com risco } \\
\text { de crédito muito baixo.A } \\
\text { capacidade de pagamento } \\
\text { dos compromissos é } \\
\text { muito forte. }\end{array}$ & $\begin{array}{l}\mathrm{B}+ \\
\mathrm{B} \\
\mathrm{B}-\end{array}$ & $\begin{array}{l}\text { B1 } \\
\text { B2 } \\
\text { B3 }\end{array}$ & $\begin{array}{l}\text { Especulativo e sujeito a alto } \\
\text { risco de crédito. Condições } \\
\text { econômicas, financeiras e de } \\
\text { negócios adversas } \\
\text { provavelmente prejudicarão a } \\
\text { capacidade ou a disposição } \\
\text { do pagamento dos } \\
\text { compromissos. }\end{array}$ \\
\hline $\begin{array}{l}\mathrm{A}+ \\
\mathrm{A} \\
\mathrm{A}-\end{array}$ & $\begin{array}{l}\text { A } 1 \\
\text { A2 } \\
\text { A3 }\end{array}$ & $\begin{array}{l}\text { Grau mediano e sujeito a } \\
\text { baixo risco de crédito. } \\
\text { Um pouco mais } \\
\text { suscetível a efeitos } \\
\text { adversos de mudanças } \\
\text { nas circunstancias e nas } \\
\text { condições econômicas do } \\
\text { que obrigações de ratings } \\
\text { mais elevadas. Entretanto } \\
\text { a capacidade dos } \\
\text { pagamentos ainda é forte. }\end{array}$ & $\begin{array}{l}\mathrm{CCC}+ \\
\mathrm{CCC} \\
\mathrm{CCC}- \\
\mathrm{CC}\end{array}$ & $\begin{array}{c}\text { Caa1 } \\
\text { Caa2 } \\
\text { Caa3 } \\
\mathrm{Ca}\end{array}$ & $\begin{array}{l}\text { Crédito pobre e sujeito a alto } \\
\text { risco de crédito. Vulneráveis } \\
\text { a defaults e dependente de } \\
\text { condições financeiras, } \\
\text { econômicas e de negócios } \\
\text { favoráveis para o pagamento } \\
\text { de suas obrigações. Em } \\
\text { condições econômicas, } \\
\text { financeiras e de negócios } \\
\text { adversas provavelmente não } \\
\text { terá capacidade de } \\
\text { pagamento. }\end{array}$ \\
\hline \multirow[t]{2}{*}{$\begin{array}{l}\mathrm{BBB}+ \\
\mathrm{BBB} \\
\mathrm{BBB}-\end{array}$} & \multirow[t]{2}{*}{$\begin{array}{l}\text { Baa1 } \\
\text { Baa2 } \\
\text { Baa3 }\end{array}$} & \multirow{2}{*}{$\begin{array}{l}\text { Risco de crédito } \\
\text { moderado. É considerado } \\
\text { um rating de grau médio, } \\
\text { com parâmetros de } \\
\text { proteção adequados. } \\
\text { Entretanto condições } \\
\text { econômicas adversas ou } \\
\text { mudanças de } \\
\text { circunstancias podem } \\
\text { conduzir a } \\
\text { emfraquecimento na } \\
\text { capacidade de pagamento } \\
\text { dos compromissos. }\end{array}$} & $\mathrm{C}$ & $\mathrm{C}$ & $\begin{array}{l}\text { Tipicamente em default, com } \\
\text { baixa possibilidade de } \\
\text { recuperação do principal ou } \\
\text { juros. Pedidos de falência ou } \\
\text { outras ações similares tem } \\
\text { sido solicitados, mas o } \\
\text { pagamento das obrigações } \\
\text { ainda estão sendo efetuados. }\end{array}$ \\
\hline & & & $\mathrm{D}$ & & Default. \\
\hline
\end{tabular}

Fonte: Damasceno (2008). 


\subsection{Estudos realizados}

Valle (2002) discute o papel das agências de ratings no provimento de informações, bem como, a importância destas na determinação do custo de captação dos diversos tomadores de recursos nos mercados de capitais. Para isso, caracterizou os aspectos fundamentais do trabalho das agências e dos ratings, onde através de revisão bibliográfica, mostrou os reflexos dos ratings na captação de recursos em mercados de dívidas, apresentou a questão do risco-país e do teto soberano na determinação dos ratings e do custo de captação de empresas. E relatou resultados de uma pesquisa realizada para o estudo dos ratings e dos custos de captação das maiores empresas de um setor industrial no período de 1991 a 1998. E a partir daí chegou-se à conclusão de que empresas com produtos relativamente homogêneos, internacionalizadas, com fluxos importantes de comércio exportador e com vantagens competitivas reconhecidas, têm maiores chances de entrar nos mercados internacionais de crédito e de financiamento como merecedoras de avaliação e de investimento.

Nadal (2003) fez um estudo de caso para um imóvel localizado no centro da Cidade de Curitiba, PR, através da utilização de regressões múltiplas para a determinação do valor de mercado de um imóvel urbano. Utilizou como principais variáveis formadoras do valor a frente do lote, a localização, a área, o padrão construtivo das edificações, o estado geral de conservação e outras. Para poder aplicar a regressão múltipla, transformou uma variável não numérica em valor numérico, através da adoção de uma variável que o represente. Concluiu que o valor de mercado de um imóvel é obtido por inferência estatística a partir do conhecimento dos valores de compra, venda e alugueis ou outra forma de geração de renda de outros imóveis que apresentem similaridades com aquele estudado.

Securato (2006) testou a aplicação do modelo binomial na formação de preços de títulos de dívida e de seus componentes adaptados à realidade brasileira, onde obteve resultados favoráveis ao modelo binomial de precificação de títulos. Os resultados levam a considerar, convenientemente, a hipótese de que os componentes contingenciais dos títulos de dívidas devem ser considerados pelos investidores em suas análises de investimento e pelas empresas em suas captações de recursos.

Damasceno (2007) fez um estudo com objetivo de averiguar se as agências de avaliação de crédito estão sendo mais severas nas análises de empresas brasileiras ao longo do tempo, onde não encontrou nenhuma evidência de que as agências de ratings estão sendo mais rigorosas em suas análises ao longo do tempo para as companhias brasileiras. Ele ainda desenvolveu uma metodologia de rating baseada no modelo probito ordinal em painel, que, através da utilização de variáveis contábeis e indicadores, seria capaz de prever o nível de rating para companhias que não possuíam nenhuma avaliação de crédito, chegou à conclusão de que as variáveis que melhor explicam as oscilações dos ratings das companhias estudadas foram o "lucro líquido sobre o total de ativos" (ROA), "dívida total sobre total de ativos" (TDA) e a variável indicadora de presença no Índice Bovespa (DIBOV).

Brito e Assaf Neto (2008) desenvolveram um modelo de classificação para avaliar o risco de crédito de empresas no mercado brasileiro, utilizando a técnica de regressão logística, aplicada a uma amostra de empresas de capital aberto classificadas como solventes ou insolventes no período entre 1994 e 2004. Utilizou como variáveis independentes os índices financeiros calculados a partir das demonstrações contábeis e utilizados para representar a situação econômico-financeira das empresas, chegando a conclusão de que as demonstrações contábeis contêm informações que possibilitam a classificação das empresas como prováveis solventes ou prováveis insolventes.

Pazzini (2008) demonstra através de uma análise de caso em uma empresa real, quais as principais variáveis utilizadas na determinação do limite de crédito e como elas podem influenciar o nível de crédito 
praticado. Concluiu que é possível utilizar a variável porte/risco para determinação de limite de crédito e que a mesma, proporciona uma melhor adequação do limite ao perfil do cliente. Sendo assim, o estabelecimento de regras de limites de crédito com base nas variáveis de porte e risco proporciona uma melhor adequação do montante de crédito de cada empresa.

\section{METODOLOGIA}

Neste trabalho, foi utilizado o método de probito ordenado em painel, por ser um modelo que já vem sendo utilizado com sucesso em diversos estudos neste campo. Além disso, este método "nos permite analisar cada fator determinante do risco separadamente" (CORBI; MENEZES-FILHO, 2004).

Eles afirmam ainda que o método de probito ordinal (ou ordenado) é uma ferramenta eficiente utilizada para modelar fenômenos cuja variável dependente seja discreta e qualitativa. "É um modelo multinomial, e sua variável dependente assume valores que estabelecem um certo ordenamento dos dados, não de forma linear, mas sim de forma a ranquear os possíveis resultados" (CORBI; MENEZES-FILHO 2006), como no caso dos ratings emitidos pelas agências classificadoras de risco.

O modelo utilizado para o cálculo do rating através de indicadores contábeis foi:

$$
E\left(Y_{i t}\right)=\alpha+\beta\left(x_{i t}^{\prime}\right)
$$

onde:

$Y_{i t}=$ variável latente que determina o rating $i$ no ano $t$;

$\alpha=$ intercepto da regressão;

$x_{i t}^{\prime}=$ vetor com valores observados para a empresa $i$ no ano $t$;

$\beta=$ vetor de parâmetro que indica a contribuição das variáveis independentes na explicação da média $y$.

Este modelo foi aplicado para o cálculo do valor para as três agências analisadas. Em todas elas foi possível observar que algumas variáveis possuem maior relevância do que outras, como o caso do Ibovespa, que foi significativo na estimação de rating das três agências analisadas. Tais como outros, porém, variam de acordo com a agência.

Os resultados apresentados nas tabelas 01, 02 e 03 foram obtidos por meio de cálculos feitos com a utilização do software EVIEWS, pois se mostrou apropriado, uma vez que o mesmo possibilita análises de dados em painel, estimações e regressões.

\subsection{Base de dados}

Foram coletados dados de demonstrativos contábeis do ano de 2009, de empresas brasileiras de capital aberto, que possuem avaliação de risco nas agências FitchRating, Moody's e Standad \& Poor's. Os dados contábeis referentes às demonstrações de resultados (receita e despesa) correspondem aos saldos acumulados de janeiro a dezembro, enquanto os dados de Balanço (ativo e passivo) correspondem ao seu valor em 31 de dezembro de 2009.

O quadro 02 apresenta as variáveis explicativas adotadas no estudo. 
Quadro 02: Variáveis explicativas adotadas no estudo

\begin{tabular}{|c|c|c|}
\hline Categoria & Nome & Método de Estimação \\
\hline Ibovespa & IBOV & Variável Dummy de presença no índice Ibovespa \\
\hline Tamanho & Ativo & Ln (Ativo Total) \\
\hline \multirow{2}{*}{$\begin{array}{l}\text { Capacidade do } \\
\text { Pagamento }\end{array}$} & $\mathrm{CJ} 1$ & Cobertura de juros $(1)=$ EBIT $* /$ Desp. Financeiras \\
\hline & $\mathrm{CJ} 2$ & $\begin{array}{l}\text { Cobertura de juros }(2)=(\text { Lucro líquido = Depreciação e Amortização - } \\
\text { Variável Capital de Giro - Variável Ativo Permanente }) \text { / Despesa } \\
\text { Financeira }\end{array}$ \\
\hline \multirow{2}{*}{$\begin{array}{l}\text { Estrutura de } \\
\text { Capital }\end{array}$} & DLP & $\begin{array}{l}\text { Endividamento de Longo Prazo/Ativo = Exigível de Longo Prazo/Ativo } \\
\text { Total }\end{array}$ \\
\hline & DT & $\begin{array}{l}\text { Endividamento Total/Ativo=(Div. Total Bruta** + Outras Obrigações } \\
\text { de Curto e Longo Prazo) / Ativo Total }\end{array}$ \\
\hline \multirow{4}{*}{ Lucratividade } & $\mathrm{MO}$ & Margem Operacional = EBIT / Receita Liquida Operacional \\
\hline & $\mathrm{ROA}$ & Lucro Líquido / Ativo Total \\
\hline & $\mathrm{CP} 1$ & Capacidade de Pagamento (1) = Dívida Total Bruta / EBITDA*** \\
\hline & $\mathrm{CP}$ & $\begin{array}{l}\text { Capacidade de Pagamento (2) = ( Lucro Líquido = Depreciação e } \\
\text { Amortização) / Dívida Total Bruta }\end{array}$ \\
\hline
\end{tabular}

Notas: $*$ EBIT = Lucro antes do pagamento de juros e impostos (do inglês Earmings Before Interest and Taxes).

** Dívida Total Bruta = Financiamento de Curto e Longo Prazo mais Debêntures de Curto e Longo Prazo.

*** EBITDA = Lucro antes do pagamento de juros, impostos, amortização e depreciação (do inglês Earmings Before Interest and Taxes, Depreciation and Amortization).

A amostra é constituída de grandes companhias, muitas delas com ações pertencentes à BM\&FBOVESPA, fator esse que atribui a elas grande liquidez, pois as ações que pertencem ao Ibovespa, divulgam informações de qualidade com transparência, que por sua vez, passam uma imagem de confiabilidade. Para indicar as ações pertencentes ao Ibovespa foi incluída a variável dummy. Pode-se observar a amostra das empresas analisadas no quadro 03.

Quadro 03: Amostra das empresas analisadas e seus respectivos setores.

(Continua)

\begin{tabular}{|l|l|}
\hline \multicolumn{1}{|c|}{ Empresa } & \multicolumn{1}{c|}{ Setor } \\
\hline Banco Bradesco S. A. & Prestação de Serviços \\
\hline Cia Siderúrgica Nacional & Transformação de aço em produtos de aço. \\
\hline Cielo S.A. & Prestação de Serviços \\
\hline Copasa - Cia de Saneamento de MG & Saneamento, Serv. Água e Gás \\
\hline Fibria Celulose S.A. & Papel e Celulose \\
\hline
\end{tabular}


Quadro 03: Amostra das empresas analisadas e seus respectivos setores.

(Conclusão)

\begin{tabular}{|l|l|}
\hline \multicolumn{1}{|c|}{ Empresa } & \multicolumn{1}{c|}{ Setor } \\
\hline Gerdau S.A. & Transformação de aço em produtos de aço. \\
\hline GOL Linhas Aéreas S.A. & Transporte Aviação Comercial \\
\hline Hipermarcas S.A. & Comércio (Atacado e Varejo) \\
\hline Itaú Unibanco Holding S.A. & Prestação de Serviços \\
\hline Itausa -Investimentos Itaú S.A. & Prestação de Serviços \\
\hline Localiza Rent a car S.A. & Serviço de Transporte e Logística \\
\hline Marfrig Alimentos S.A. & $\begin{array}{l}\text { Alimentos -Exploração de atividades } \\
\text { frigoríficas. }\end{array}$ \\
\hline MPX Energia S.A. & Emp. de Adm. Part. - Energia Elétrica \\
\hline OGX Petróleo e Gás Participações S/A & Extração de gás e petróleo \\
\hline Paranapanema S.A. & Metalúrgica e Siderúrgica \\
\hline Petróleo Brasileiro S.A. - PETROBRAS & Extração de gás e petróleo \\
\hline Susano -Papel e Celulose S.A. & Indústria de papel e celulose \\
\hline Usiminas Siderúrgicas de Minas Gerais S.A. & Transformação de aço em produtos de aço. \\
\hline Vale S. A. & Mineração \\
\hline Weg S.A. & Emp. Adm. Part. - Máqs, Equip. Veíc. e Peças \\
\hline
\end{tabular}

Os graus de rating utilizados foram os emitidos pelas agências citadas acima, referentes à classificação Escala Nacional de Crédito de Longo Prazo. A opção pela classificação Escala Nacional de Crédito de Longo Prazo foi escolhida pelo fato dessa avaliação atribuir um menor peso no risco soberano nacional.

Para cada grau de rating foi atribuído um valor, associados à variável independente $Y_{\mathrm{it}}$, da seguinte forma: 0 para AAA, 1 para AA, e assim sucessivamente, conforme mostra o quadro 04.

Quadro 04: Variável Categorizada Y e Classe Rating

\begin{tabular}{|c|c|}
\hline Variável Categorizada $\mathbf{Y}$ & Grau de Rating \\
\hline 0 & AAA \\
\hline 1 & AA \\
\hline 2 & A \\
\hline 3 & BBB \\
\hline 4 & BB e B \\
\hline 5 & CCC \\
\hline 6 & CC, C e D \\
\hline
\end{tabular}

\section{ANÁLISE DOS RESULTADOS}

A Tabela 1 apresenta os resultados da regressão entre os indicadores financeiros contábeis e a 
classificação do Rating pela instituição Fitch Rating.

Tabela 01: Modelo para previsão de Rating da Fitch Rating

\begin{tabular}{lccc}
\hline \multicolumn{1}{c}{ Variável } & Coef. & Estat. T & p-valor \\
\hline Ibov & $\mathbf{0 , 7 6}$ & $\mathbf{1 , 9 0}$ & $\mathbf{0 , 0 9}$ \\
Tamanho (R\$ mil) & $\mathbf{0 , 0 0}$ & $\mathbf{- 4 , 5 7}$ & $\mathbf{0 , 0 0}$ \\
CJ1 & 0,10 & 0,91 & 0,38 \\
CJ2 & 0,00 & $-0,60$ & 0,56 \\
DLP & $-1,65$ & $-0,74$ & 0,48 \\
DT & 0,97 & 0,41 & 0,69 \\
MO & 0,16 & 0,59 & 0,57 \\
ROA & $-0,70$ & $-0,11$ & 0,92 \\
CP1 & $\mathbf{0 , 1 4}$ & $\mathbf{1 , 9 5}$ & $\mathbf{0 , 0 8}$ \\
CP2 & 0,96 & 0,53 & 0,61 \\
R ${ }^{2}$ & 0,79 & Estat. F & 4,13 \\
Durbin Watson & 2,68 & p-valor & 0,02 \\
\hline
\end{tabular}

Dos valores apresentados na Tabela 1 observa-se que as variáveis Ibov, Tamanho e CP1 foram significativas a $10 \%$, uma vez que os p-valores estavam abaixo de 0,1 . No que se refere o modelo de regressão, o p-valor 0,02 da Estatística $\mathrm{F}$ revela uma significância de $95 \%$ das variáveis adotadas no modelo. O que demonstra o bom ajustamento às variáveis analisadas.

O resultado de $R^{2}$ encontrado na estimação do rating da Fitch Rating foi de 0,79 , isso mostra que o modelo é capaz de explicar $79 \%$ da variação na variável dependente, sendo que das três agências analisadas, foi a que apresentou maior quantidade de acertos.

O quadro 05 mostra a comparação dos ratings encontrados pelo modelo, com o rating atribuído pela Fitch Rating.

Quadro 05: Comparação do rating encontrado com o atribuído pela Fitch Rating.

\begin{tabular}{|l|c|c|c|l|c|c|c|}
\hline \multicolumn{1}{|c|}{ Empresas } & $\begin{array}{c}\text { Total } \\
\text { (rating) }\end{array}$ & $\begin{array}{c}\text { Arredon } \\
- \\
\text { damento }\end{array}$ & $\begin{array}{c}\text { Rating } \\
\text { da } \\
\text { Agência }\end{array}$ & Empresas & $\begin{array}{c}\text { Total } \\
\text { (rating) }\end{array}$ & $\begin{array}{c}\text { Arredon } \\
- \\
\text { damento }\end{array}$ & $\begin{array}{c}\text { Rating } \\
\text { da } \\
\text { Agência }\end{array}$ \\
\hline Bradesco & $\begin{array}{c}0,59103 \\
3\end{array}$ & 1 & 0 & Marfrig & 1,761715 & 2 & 3 \\
\hline Cielo & $\begin{array}{c}4,16132 \\
8\end{array}$ & 4 & 4 & MPX & 2,102113 & 2 & 2 \\
\hline Copasa & $\begin{array}{c}0,94325 \\
1\end{array}$ & 1 & 1 & OGX & 1,909961 & 2 & 2 \\
\hline Fibria & $\begin{array}{c}1,76264 \\
3\end{array}$ & 2 & 2 & $\begin{array}{l}\text { Paranapane } \\
\text { ma }\end{array}$ & 1,05708 & 1 & 1 \\
\hline Gerdau S.A. & $\begin{array}{c}1,42445 \\
6\end{array}$ & 1 & 1 & Petrobrás & $-0,16575$ & 0 & 0 \\
\hline GOL & $\begin{array}{c}1,93489 \\
3\end{array}$ & 2 & 3 & Sid Nacional & 1,316952 & 1 & 1 \\
\hline Hypermarcas & $\begin{array}{c}0,37826 \\
5\end{array}$ & 0 & 2 & Suzano & 0,925464 & 1 & 1 \\
\hline Itaú Unibanco & $-0,03088$ & 0 & 0 & Usiminas & 1,273879 & 1 & 1 \\
\hline Itausa & $-0,45016$ & 0 & 0 & Vale & 0,271947 & 0 & 0 \\
\hline Localiza & $\begin{array}{c}2,05124 \\
7\end{array}$ & 2 & 1 & Weg S.A. & 1,160701 & 1 & 1 \\
\hline
\end{tabular}


Os valores apresentados no Quadro 5 evidenciam que o modelo proposto para o cálculo do Rating com base nos indicadores contábil financeiro foram satisfatórios com aqueles apresentados pela Fitch Rating. A porcentagem de acerto observada foi de 75\% (Gráfico 1), do restante, 20\% ficaram bem próximos ao valor do rating atribuído pela agência.

Gráfico 01: Porcentagem de acertos obtidos para a previsão de rating da Fitch Rating.

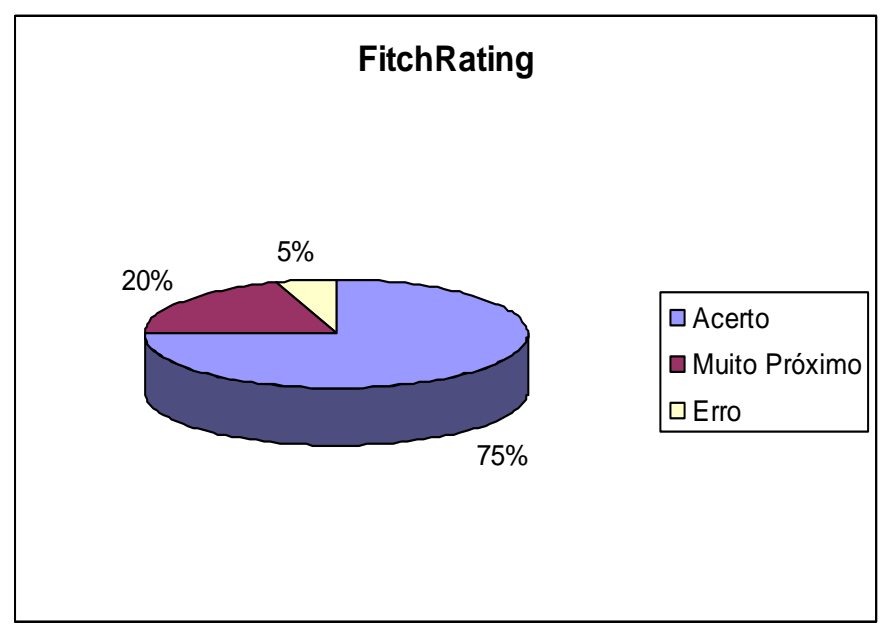

A tabela 02 mostra que para a agência Moody's, além das variáveis IBOV, Tamanho e CP1, também se apresentou relevante, a variável CP2 significativa a 10\%. Assim como a CP1, a CP2 mede a cobertura de juros, através do Lucro Líquido, Depreciação e Amortização, Capital de Giro, Ativo Permanente e Despesas Financeiras.

O p-valor foi de 0,04, ainda aceitável, pois está dentro do parâmetro imposto por Andrade (2009), ou seja, ainda pode-se considerar os $95 \%$ de certeza quanto à relevância das variáveis adotadas no modelo. O DW, embora menor que o obtido pela Fitch Rating, também ficou dentro do aceitável, ou seja, acima de 2,50 .

Tabela 02: Modelo para previsão de Rating da Moody's

\begin{tabular}{lccc}
\hline \multicolumn{1}{c}{ Variável } & Coef. & Estat. T & p-valor \\
\hline Ibov & $\mathbf{1 , 4 3}$ & $\mathbf{2 , 5 8}$ & $\mathbf{0 , 0 3}$ \\
Tamanho (R\$ mil) & $\mathbf{0 , 0 0}$ & $\mathbf{- 4 , 0 6}$ & $\mathbf{0 , 0 0}$ \\
CJ1 & $-0,05$ & $-0,37$ & 0,72 \\
CJ2 & 0,00 & $-0,03$ & 0,98 \\
DLP & 1,27 & 0,41 & 0,69 \\
DT & $-4,71$ & $-1,46$ & 0,18 \\
MO & 0,37 & 0,97 & 0,36 \\
ROA & 4,80 & 0,53 & 0,61 \\
CP1 & $\mathbf{0 , 3 7}$ & $\mathbf{3 , 7 0}$ & $\mathbf{0 , 0 0}$ \\
CP2 & $\mathbf{5 , 5 7}$ & $\mathbf{2 , 2 2}$ & $\mathbf{0 , 0 5}$ \\
R & 0,74 & Estat. F & 3,20 \\
Durbin Watson & 2,62 & p-valor & 0,04 \\
\hline
\end{tabular}

Os resultados da Tabela 02 evidenciam que a regressão para o rating da agência Moody's apresenta o valor $R^{2}$ igual a 0,74 , ou seja, $74 \%$ de proximidade entre os valores encontrados com os esperados. $\mathrm{O}$ que demonstra o bom ajustamento do modelo. 
Analisando o Gráfico 02, pode-se observar que a porcentagem de acertos foi de $60 \%$, e de $35 \%$ para valores bem próximos do atribuído pela agência, e 5\% dos resultados foram diferentes do esperado em mais de 1 grau de diferença, conforme quadro 06. Valores extraídos também do Quadro 6.

Quadro 06: Comparação do rating encontrado com o atribuído pela Moody’s.

\begin{tabular}{|c|c|c|c|c|c|c|c|}
\hline Empresas & $\begin{array}{c}\text { Total } \\
\text { (rating) }\end{array}$ & $\begin{array}{l}\text { Arredon- } \\
\text { damento }\end{array}$ & $\begin{array}{c}\text { Rating } \\
\text { da } \\
\text { Agência }\end{array}$ & Empresas & $\begin{array}{c}\text { Total } \\
\text { (rating) }\end{array}$ & $\begin{array}{l}\text { Arredon- } \\
\text { damento }\end{array}$ & $\begin{array}{c}\text { Rating } \\
\text { da } \\
\text { Agência }\end{array}$ \\
\hline Bradesco & $\begin{array}{c}1,24612 \\
8\end{array}$ & 1 & 1 & Marfrig & $\begin{array}{c}2,99488 \\
8\end{array}$ & 3 & 4 \\
\hline Cielo & $\begin{array}{c}3,98734 \\
3\end{array}$ & 4 & 4 & MPX & $\begin{array}{c}3,14102 \\
3\end{array}$ & 3 & 3 \\
\hline Copasa & 2,42825 & 2 & 2 & OGX & $\begin{array}{c}3,89173 \\
1\end{array}$ & 4 & 4 \\
\hline Fibria & $\begin{array}{c}2,44885 \\
4\end{array}$ & 2 & 3 & $\begin{array}{l}\text { Paranapan } \\
\text { ema }\end{array}$ & $\begin{array}{c}1,73922 \\
2\end{array}$ & 2 & 2 \\
\hline Gerdau S.A. & $\begin{array}{c}3,18425 \\
2\end{array}$ & 3 & 3 & Petrobrás & $\begin{array}{c}0,48438 \\
2\end{array}$ & 0 & 0 \\
\hline GOL & $\begin{array}{c}2,92293 \\
1\end{array}$ & 3 & 4 & $\begin{array}{l}\text { Sid } \\
\text { Nacional }\end{array}$ & $\begin{array}{c}1,51149 \\
3\end{array}$ & 2 & 1 \\
\hline Hypermarcas & $\begin{array}{c}2,12555 \\
3\end{array}$ & 2 & 1 & Suzano & $\begin{array}{c}0,83784 \\
9\end{array}$ & 1 & 2 \\
\hline $\begin{array}{l}\text { Itaú } \\
\text { Unibanco }\end{array}$ & 0,83529 & 1 & 1 & Usiminas & 1,68045 & 2 & 1 \\
\hline Itausa & $\begin{array}{c}- \\
0,34833\end{array}$ & 0 & 0 & Vale & $\begin{array}{c}1,15585 \\
6\end{array}$ & 1 & 1 \\
\hline Localiza & $\begin{array}{c}2,86179 \\
5\end{array}$ & 3 & 1 & Weg S.A. & $\begin{array}{c}1,00547 \\
6\end{array}$ & 1 & 1 \\
\hline
\end{tabular}

Gráfico 02: Porcentagem de acerto obtidos para a previsão de rating da Moody’s.

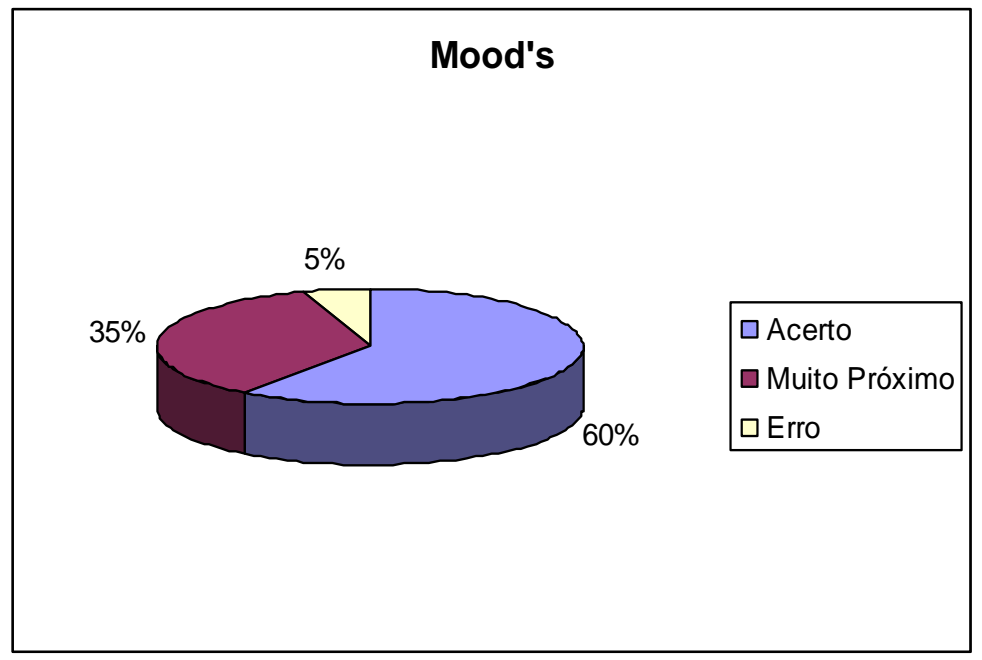

A tentativa de previsão dos ratings da Standad \& Poor's foi a que apresentou resultado mais distante do esperado. Conforme a Tabela 3, o modelo foi capaz de explicar apenas $66 \%$ da variação na variável dependente. Para a Stand \& Poor's, a variável mais significativa foi o tamanho da empresa, conforme mostra a Tabela 03, e ainda assim seu valor não se mostrou tão satisfatório, quanto ao apresentado pelas variáveis testadas nas outras duas agências. 
Tabela 03: Modelo para previsão de Rating da Standad \& Poor's

\begin{tabular}{lccc}
\hline \multicolumn{1}{c}{ Variável } & Coef. & Estat. T & p-valor \\
\hline Ibov & 1,34 & 1,49 & 0,17 \\
Tamanho (R\$ mil) & 0,00 & $-1,82$ & 0,10 \\
CJ1 & 0,11 & 0,44 & 0,67 \\
CJ2 & 0,00 & $-0,25$ & 0,81 \\
DLP & $-0,01$ & 0,00 & 0,99 \\
DT & 0,49 & 0,09 & 0,93 \\
MO & 0,01 & 0,02 & 0,99 \\
ROA & $-4,03$ & $-0,28$ & 0,79 \\
CP1 & 0,16 & 0,98 & 0,35 \\
CP2 & 3,26 & 0,81 & 0,44 \\
R2 & 0,66 & Estat. F & 2,55 \\
Durbin Watson & 2,41 & p-valor & 0,08 \\
\hline
\end{tabular}

O p-valor também ficou acima do padrão proposto por Andrade (2009), ou seja, não atingiu os 95\% de confiabilidade. E o Durbin Watson observado, ficou abaixo do que seria um bom resultado.

Quadro 07: Comparação do rating encontrado com o atribuído pela S\&P.

\begin{tabular}{|l|c|l|c|l|l|l|c|}
\hline \multicolumn{1}{|c|}{ Empresas } & $\begin{array}{c}\text { Total } \\
(\text { rating })\end{array}$ & $\begin{array}{c}\text { Arredon- } \\
\text { damento }\end{array}$ & $\begin{array}{c}\text { Rating } \\
\text { da } \\
\text { Agência }\end{array}$ & Empresas & $\begin{array}{c}\text { Total } \\
\text { (rating) }\end{array}$ & $\begin{array}{c}\text { Arredon- } \\
\text { damento }\end{array}$ & $\begin{array}{c}\text { Rating } \\
\text { da } \\
\text { Agência }\end{array}$ \\
\hline Bradesco & 2,03129 & 2 & 0 & Marfrig & 2,29565 & 2 & 4 \\
\hline Cielo & $\begin{array}{c}4,76979 \\
3\end{array}$ & 5 & 5 & MPX & 2,306734 & 2 & 2 \\
\hline Copasa & $\begin{array}{c}1,45579 \\
9\end{array}$ & 1 & 2 & OGX & 2,601368 & 3 & 3 \\
\hline Fibria & $\begin{array}{c}2,96740 \\
9\end{array}$ & 3 & 4 & $\begin{array}{l}\text { Paranapa } \\
\text { nema }\end{array}$ & 2,033932 & 2 & 3 \\
\hline Gerdau S.A. & $\begin{array}{c}2,84756 \\
5\end{array}$ & 3 & 3 & Petrobrás & 1,853345 & 2 & 1 \\
\hline GOL & $\begin{array}{c}2,95877 \\
9\end{array}$ & 3 & 1 & $\begin{array}{l}\text { Sid } \\
\text { Nacional }\end{array}$ & 2,683032 & 3 & 4 \\
\hline Hypermarcas & $\begin{array}{c}0,56084 \\
3\end{array}$ & 1 & 2 & Suzano & 1,527718 & 2 & 1 \\
\hline $\begin{array}{l}\text { Itaú } \\
\text { Unibanco }\end{array}$ & $\begin{array}{c}1,55496 \\
1\end{array}$ & 2 & 3 & Usiminas & 2,159099 & 2 & 3 \\
\hline Itausa & $\begin{array}{c}0,96920 \\
6\end{array}$ & 1 & 2 & Vale & 1,594872 & 2 & 0 \\
\hline Localiza & $\begin{array}{c}2,61559 \\
4\end{array}$ & 3 & 1 & Weg S.A. & 1,341671 & 1 & 1 \\
\hline
\end{tabular}

A porcentagem de acerto também foi menor que das outras duas agências, sendo $25 \%$ de acertos, $50 \%$ para valores muito próximos ao valor atribuído pela agência e $25 \%$ com valores com distância maior que um grau do esperado. A partir daí, pode-se concluir que para a $\mathrm{S} \& \mathrm{P}$ existem outros fatores que possuem grande relevância e, no entanto, não foram testados pelo modelo proposto. 
Gráfico 03: Porcentagem de acerto obtidos para a previsão de rating da Standad \& Poor's.

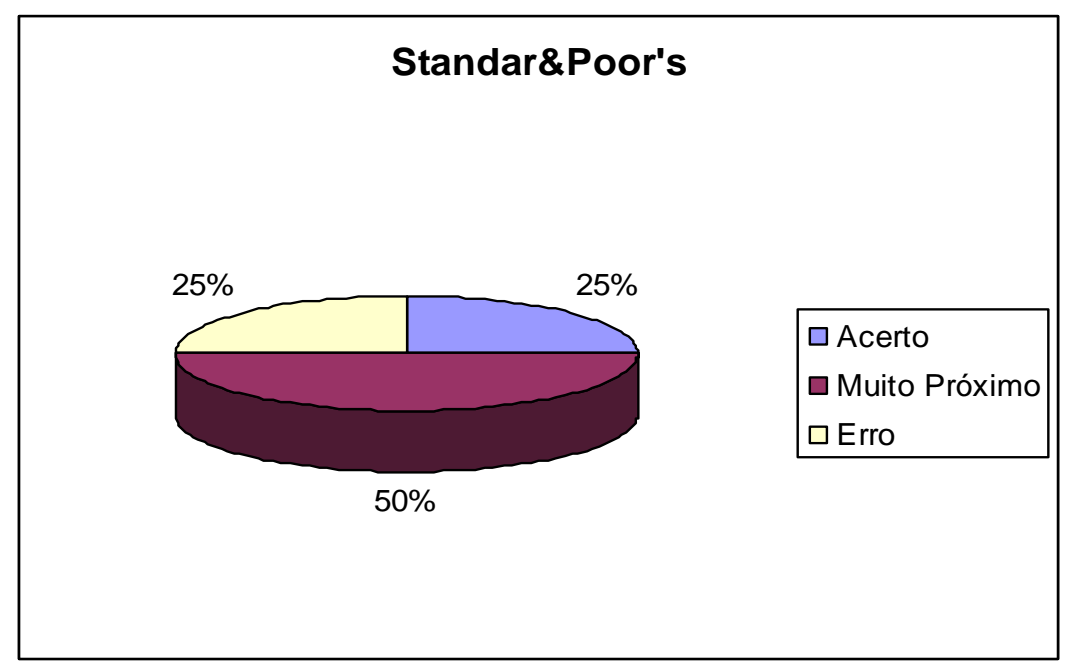

De acordo com os resultados da estatística-F, que representa o conjunto de variáveis testadas no modelo aplicado às três agências, as variáveis testadas se mostraram mais significativas para a Fitch Rating do que para as demais.

Dentre elas, o conjunto de variáveis que mostrou-se menos significativo, foi a Standad \& Poor's, o que leva a acreditar que além dessas variáveis, existem outros fatores que são relevantes no método de determinação de rating da S\&P.

No geral, pode-se dizer que o método foi capaz de acertar o rating atribuído pelas agências em $53,33 \%$, e chegou muito próximo do valor esperado em $35 \%$ das vezes.

\section{CONSIDERAÇÕES FINAIS}

Por meio desse modelo foi possível validar o método utilizado, uma vez que, fazendo uma comparação entre os ratings estabelecidos pelas agências de rating com os calculados por este estudo, nota-se que o método conseguiu prever corretamente cerca de 53,33\% de toda a amostra, e chegou bem próximo de outros $35 \%$.

No entanto, ainda existem alguns aspectos que influenciaram negativamente os resultados, tais como, o grau de alavancagem de certas empresas, onde se verificou maior discrepância entre os ratings das agências evidenciadas e os calculados por meio desta pesquisa.

Outro fator foi o fato da amostra ser relativamente pequena e muito mista, contendo empresas de vários segmentos distintos do mercado o que impede a generalização dos resultados para as demais empresas.

Apesar das limitações e da margem de erro, os resultados foram condizentes com o esperado, pois na maior parte da amostra foi possível acertar ou chegar próximo ao rating atribuído pela agência. Sendo assim, pode-se dizer que este método de estimação de rating é bastante viável para a prevenção de ratings de empresas que não são avaliadas por nenhuma agência.

Ademais, sugerem-se outros estudos na área utilizando amostras mais amplas, com as demais agências de rating, bem como a aplicação de mais variáveis e índices contábeis à técnica aplicada a fim de tornar os resultados mais confiáveis. 


\section{REFERENCIAS}

ANDRADE, C. H. C.; Econometria Aplicada - 2009. Disponível em:

http://www.ppge.ufrgs.br/sabino/eco02007/aula1-2.pdf Acesso em: 08 abr. 2010.

ASSAF NETO, A.. Mercado Financeiro. 6. ed. São Paulo: Atlas, 2005.

BRITO, G. A. S.; ASSAF NETO, A.. Modelo de classificação de Risco de Crédito de Empresas. Revista de Cont. e Finanças - USP, v.19, n. 46, p. 18-29, jan/abr. 2008.

CORBI, R.B.; MENEZES-FILHO, N.A. Os determinantes empíricos da felicidade no Brasil. Revista de Economia Política, São Paulo, v.26, n4, p.120-140, 2006. Disponível em < www.scielo.br/scielo.php?script=sci_artext\&pid $>$. Acesso em: 18 jun. 2010.

DAMASCENO, D. L. Determinação de ratings de crédito para empresas brasileiras através de indicadores contábeis. São Paulo, 2007. 47 f. Dissertação (Mestrado) - Faculdade Ibmec São Paulo.

GIL, A.C.. Como elaborar projetos de pesquisa. 4. ed. São Paulo: Atlas, 2002.

GODOI, A. C. de; YOSHINO, J. A.; OLIVEIRA, R. de D. Risco de crédito e alocação ótima para uma carteira de debêntures. Estud. Econ., São Paulo, v. 38, n. 2, p. 349-372, 2008 . Disponível em $<$ http://www.scielo.br/scielo.php?script=sci_arttext\&pid=S0101-

41612008000200006\&lng=pt\&nrm=iso>. acessos em 18 abr. 2016. http://dx.doi.org/10.1590/S0101$\underline{41612008000200006 .}$.

MACRODADOS Sistemas Gerenciais - Solução integrada para análise econômica; Disponível em:< http://www.macrodados.com.br/ajuda/Econometria_Parte2.htm > Acesso em: 08 abr. 2010.

NADAL, C.A. et al. Testes Estatísticos Utilizados para validação de regressões múltiplas aplicadas na avaliação ed imóveis urbanos. Bol. Ciênc. Geod. Curitiba, v. 9, n. 2, p.243-262, jul-dez, 2003.

PAZZINI, F.L.S.et al. Análise dos fatores que influenciam na concessão do limite de crédito: uma aplicação pratica. - 2008 Disponível em: <http://www.ead.fea.usp.br/Semead>. Acesso em: 18 jun. 2010.

SECURATO, J. R. Bônus empresariais: Um título semelhante às debêntures que poderá ter um significativo mercado secundário. Revista Álvares Penteado, v. 1, n.1 p. 78-92, dez 1998.

SECURATO,J. R. et al. Precificação de títulos de dívida corporativa e seus componentes pelo modelo binominal. Revista de Administração - USP, v.41, n. 1, p. 18-28, jan/fev/mar 2006.

SILVA, M.A. da. Elaboração de um modelo de análise de concessão de crédito para pessoas físicas de um banco. 2003. p. 142. Dissertação b (Mestrado em Engenharia de Produção) - Programa de pos graduação em Engenharia de produção, Florianópolis.

SILVA, J. P. Gestão e análise de risco de crédito. São Paulo: Atlas, 1997.

SND. Base de dados. Disponível em: www.debêntures.com.br acesso em: 19 mar. 2010.

SR RATING - Agência Classificadora de Risco, disponível em http://www.srrating.com.br/ Acesso em 30 maio 2010.

TIMOSSI, L.da S.. Correlações entre a qualidade de vida e a qualidade de vida no trabalho em colaboradores das indústrias de laticínios. Revista de Gestão Industrial - UTFPR, fev. 2009; Disponível em: www.pg.utfpr.edu.br/

VALLE, M.R.. Mercados de Bonds: risco, rating e custo de captação. Revista de Administração - USP, v.37, n.2, p. 46-56, abr./jun. 2002. 